\title{
Re-reading in stylistics
}

\begin{abstract}
Cognitive stylistics is primarily concerned with the cognitive processes - mental simulations experienced by readers. Most cognitive stylisticians agree that experiences of reading texts are dynamic and flexible. Changes in the context of reading, our attentional focus on a given day, our extra background knowledge about the text, and so on, are all factors that contribute to our experience of a fictional world. A second reading of a text is a different experience to a first reading.

As researchers begin to systematically distinguish between the 'solitary' and 'social' readings that constitute reading as a phenomenon (Peplow et al., 2016), the relationship between multiple readings and the nature of their processing become increasingly pertinent. In order to explore this relationship, firstly we examine the different ways in which re-reading has previously been discussed in stylistics, grounding our claims in an empirical analysis of articles published in key stylistics journals over the past two decades. Next, we draw on reader response data from an online questionnaire in order to assess the role of re-reading and the motivations that underpin it. Finally, we describe an exercise for the teaching of cognitive stylistics, specifically applying schema theory in literary linguistic analysis (Cook, 1994), which illustrates the need to distinguish between readings as part of an analysis. Through these three sections we argue that our experiences of texts should be considered diachronically, and propose that the different readings that make up an analysis of a text should be given greater attention in stylistic research and teaching.
\end{abstract}

\section{Keywords}

Re-reading, schema theory, pedagogical stylistics, The Girl With All The Gifts, reader response

\subsection{Introduction}

The recent turn to the observation of real readers in stylistics has led to increasing attention to the different types of reading and reading contexts in which texts are experienced. Analysing naturalistic data from book clubs, Swann and Allington (2009: 252-3) observe that 'reading group talk is one in a series of acts of reading, including individual private reading, and occasionally re-reading in the light of discussion, consultation of other readings such as published reviews, writing up members' own reviews for newsletters'. More recently, Peplow et al. (2016) distinguish between 'solitary readings' in which we engage with texts individually, and those 'social readings' in settings such as classrooms, reading groups and online forums, which often follow or precede a personal response to a text. A related consideration is the fact that readers' engagement with texts typically occurs over extended 
periods of time, in multiple sittings. Even in its solitary, internalised form, readers often read and reread the same texts on multiple occasions, and do so for a range of reasons.

One motivation for re-reading is in the teaching and practice of stylistic analysis. Spitzer's (1948) 'philological circle' suggested that initial impressions of a literary text can be validated through linguistic analysis, which can in turn enrich our interpretation and appreciation of a text and, in doing so, prompt further analysis. Indeed, Spitzer regarded re-reading as a fundamental method for approaching a text:

How often, with all the theoretical experience of method accumulated in me over the years, have I stared blankly, quite similar to one of my beginning students, at a page that would not yield its magic. The only way out of this state of unproductivity is to read and reread. (Spitzer, 1948: 27)

While methods vary in contemporary stylistic research, the cyclical process of interpretationanalysis-interpretation represents a basic and prevalent approach to textual analysis (see also Short, 1996: 357). This practice raises questions for the way in which stylistic analysis is taught, particularly in an undergraduate classroom setting. In our own teaching of stylistics, we are regularly faced with the decision of whether to give our students a text to read ahead of the following class, or to elicit their first experience of it during class itself, particularly when the text in question features a 'twist' (Emmott, 2003) or a 'reveal' of plot-significant information (see Harrison and Nuttall, forthcoming). This decision gains particular importance when teaching cognitive stylistics, the object of study for which is the reading process itself and its felt experience (Stockwell, 2002: 2). Stylistics has always been a pedagogically driven discipline, concerned with the transparency and replicability of its methods (Stockwell and Whiteley, 2014: 4). The role of re-reading in readers' experiences of texts, including those that take place in classrooms, is therefore an important - if massive - question that this article will begin to address.

This article investigates re-reading from three different perspectives. Firstly, in section 1.2, we explore how re-reading has been treated in previous published work in stylistics, through an examination of the contexts in which 're-reading' and 'second reading' are used in papers published in Language and Literature and Journal of Literary Semantics between 1997 and 2017. In section 1.3, we present findings from an online survey carried out with 60 undergraduate students of English Language and Literature, which aimed to gain an insight into motivations for re-reading. In section 1.4, we present a different kind of reader response study, this time featuring students from our own stylistics classrooms. We outline a simple classroom exercise which makes use of systematic rereading as a method for the teaching of schema theory and its application to M.R. Carey's (2014) novel The Girl With All The Gifts. This exercise demonstrates, firstly, the significance of re-reading 
processes in cognitive stylistics and, secondly, the methodological importance of an explicit delineation of readings for its transparency and replicability in practice.

\section{2. 'Re-reading' in published stylistic research}

In order to understand the way in which re-reading is treated in stylistics, we examined articles published in two stylistics journals (Language and Literature and Journal of Literary Semantics) over the past twenty years (1997-2017). After excluding book reviews, review articles, editorials and responses, this left us with a sample of 421 articles across these two sources. Our methods of analysis replicate those of Allington and Swann (2009) in their examination of instances of read(s), reader $(s)$ and reading $(s)$ in Language and Literature between 2004 and 2008. While Allington and Swann found 75 instances of these terms in a sample of just 85 papers, we expected to find much fewer references to re-reading and so a larger sample seemed appropriate. A search for re-read, reread and second read in these two sources across this twenty-year period gave us $\operatorname{re}-\operatorname{read}(s), \operatorname{reread}(s), \operatorname{re}$ reading, rereading $(s)$ and second reading $(s)$. We then discounted any articles in which instances of these terms were found only in the references.

As expected, the frequency of instances was relatively low, occurring in 48 articles in our sample of 420. This result can be interestingly compared with that found by Swann of Allington (2009). In the 233 articles in our sample that came from Language and Literature, just 29 (12\%) of these contained instances of our search terms. This suggests that, while reading practices and discussions of real, ideal or implied readers (Iser, 1974) are pervasive in stylistics (in $88 \%$ of the papers in Swann and Allington's sample), explicit discussion of re-readings or multiple readings through time are far less common. Closer examination of the contexts in which these instances were found reveals a number of different uses of these terms. Table 1 lists the different groups identified in our sample through manual analysis and the number of instances we attributed to each.

\begin{tabular}{|l|l|}
\hline Group & No. of instances \\
\hline Re-reading in stylistic analysis & 8 \\
\hline Experience of re-reading based on introspection or speculation & 11 \\
\hline based on theory & 7 \\
\hline based on experimental reader response research & 7 \\
\hline based on observation of real readers & 4 \\
\hline Re-interpretation/alternative readings & 5 \\
\hline Re-reading as part of narrative plot & 4 \\
\hline
\end{tabular}

Table 1: References to re-reading in two stylistics journals (1997 - 2017) 
Firstly, we can discount some less relevant uses from our discussion, including references to a character re-reading as part of a narrative plotline and references to re-reading the work of a particular scholar (e.g. 'Rereading Bakhtin' [Wood, 2004]). Another group of articles in our sample referred to what, in context, would seem to be quite different from the physical, diachronic re-reading of a text in which we are interested. These references to re-reading describe the act of producing an alternative interpretation of a text through representation, for example in 're-reading historical events through their depiction in literary texts' (Bhaya Nair, 2003: 114). For our purposes, we distinguish these processes as 're-interpretation'. Also included in this group are instances in which 'first' and 'second' readings do not necessarily refer to successive physical encounters with a text, but rather reflect the order in which alternative interpretations are described or presented by the reader/analyst. In the below example, the second reading described is a social reading (Peplow et al., 2016) which emerges during a group discussion:

However, as the students in these seminars went on to discuss their responses to the text in more detail, a second reading emerged around which an equal level of consensus was reached. In the Madrid seminar, for example, around half (13 of 30 participants) identified the poem as being about a relationship that had failed. (Gavins and Stockwell, 2012: 43)

The remaining groups, to which most instances in our sample apply, illustrate a number of different ways in which re-reading is discussed. Firstly, references to re-reading are often seen in descriptions of the practice of stylistic analysis. In two pedagogically focussed articles this practice was described in the context of teaching/learning:

Most web-based work is based on the reading of the written word, and writing is less natural than speech, in the sense that reading and writing have to be formally learned. Writing allows the writer to be accurate and precise, and the reader to re-read; but the reader seems to have to work harder to process writing (Short, 2006: 246-7)

You will now need to re-read all of these texts. You will now start to flesh out your preliminary observations in greater detail. Start to look at the actual textual detail of linguistic levels. (Burke, 2010: 81)

More often, however, the re-reading described is carried out by the researcher themselves:

Thus in my reading of the metrical structure of 'The Dance' the syllable count per line varies from eight to 11 and the number of stresses from three to four. But when rereading it aloud, I hear (and metaphorically feel!) that its metrical ground plan is not drawn line by line, but ranges right across the poem. (Verdonk, 2005: 238) 
To find instances of chiasmus in McGahern's fiction all of his novels were reread with a specific regard to mirror-image repetitions of words or phrases that take the positions $1>2>3: 3<2$ (Prusse, 2012: 368).

The focus on difficulty and challenge is interesting because it taps into experiential aspects of reading which are minimised by the re-reading involved in close stylistic analysis (Whiteley and Canning, 2017: 80).

On many of the occasions in which this analytical procedure is referred to, analysts describe experiential differences between their first and second reading. In a further eleven of the references in our sample, researchers go on to suggest such experiential differences in other readers on the basis of such introspection. In the two examples below, from the same issue of Language and Literature, suggestions are made regarding re-readings of texts that are surprising, or which feature a reveal:

Even more surprising is the fact that he finds a key to open the back door. [...] The protagonist's taking off his muddy shoes before going to the bedroom where a woman is sleeping might, on rereading, sound like a clear anomaly for a murderer but at this stage the reader is likely to be ready to find alternative explanations that fit in the familiar scenario: he took off his shoes to reduce potential noise for instance. (Sorlin, 2015: 48)

While critical readers such as those identified at the end of section 5.2 may recognise this mind style during a first reading of the text, for a large proportion of readers, I would suggest, the attribution of this construal to Neville's mind style will emerge during their second reading, as part of a radically altered experience of this character and the vampires he plagues. (Nuttall, 2015: 35)

In another smaller group of seven articles, the experience of re-reading is proposed on the basis of a specific theory. These theories include Sternberg's (2001) theory of narrativity and Furlong's (1996) relevance theoretical account of 'spontaneous' and 'non-spontaneous' reading:

In terms of Furlong $(1996,2008)$, my focus here, then, is on the "spontaneous" interpretation during an initial reading, as distinct from the kind of "non-spontaneous" interpretation that becomes available on a rereading. (Caink, 2008: 125)

Finally, a further seven of the references to re-reading describe its experience in the context of experimental reader response research. Here, re-reading is discussed in relation to readers' responses to texts under experimental conditions (Bray, 2007; Castiglione, 2017). In some, re-reading is used as 
an experimental protocol, with participants invited to read a text twice, or multiple times, as part of a study:

The two experiments presented in Section 2 apply Dixon et al.'s (1993) re-reading paradigm in order to test whether deviation in film produces foregrounding effects. (Hakemulder, 2007: 128)

A re-reading task was set up: in the first reading, participants read for general comprehension, and in the second reading, they were asked to identify whose point(s) of view each passage is narrated from (Cui, 2017: 122).

Notably, in the above instances and others in our sample, re-reading is not itself the object of study, but is rather a means of investigating how readers process specific textual phenomena such as foregrounding (Emmott, Sanford and Morrow, 2006; Hakemulder, 2007; Yaron, 2003), metaphor (Gibbs, 2002; cited in Csatár, Pethő and Tóth, 2006) or shifts in narrative point of view (Cui, 2017). In the two examples above, the researchers replicate the methods of earlier studies by Dixon et al. (1993) and Millis (1995) which pre-date our sample. These influential studies for stylistic accounts of re-reading are briefly summarised below.

Dixon et al.'s (1993) 're-reading paradigm' derives from their study of literariness, which they define in terms of 'emergent effects' that develop after an initial reading. In their study, Dixon and colleagues asked participants to read a text twice successively and to evaluate it after each reading on a number of scales intended to measure 'depth of appreciation'. They compared ratings for two versions of the short story 'Emma Zunz' by Jorge Luis Borges, one of which had been altered to remove its narratorial ambiguity, and found that the original version gained significantly more in 'depth of appreciation' on a second reading for frequent readers. This re-reading paradigm has since been applied in studies of literary appreciation in response to foregrounding in the work of Hakemulder and colleagues (Hakemulder, 2004, 2007; Kuijpers and Hakemulder, 2017; Zyngier, van Peer and Hakemulder, 2007). However, while adding support to Dixon et al.'s discovery of 'emergent effects' across readings, what 'it is exactly that emerges', or the nature of the processing and resultant reader experiences during re-reading, remains unclear (Kuijpers and Hakemulder, 2017: 2). Kuijpers and Hakemulder (2017) propose that an increase in comprehension may underlie increased appreciation, drawing connections with the changing allocation of cognitive resources during rereading observed in the work of Millis and colleagues (Millis, 1995; Millis et al., 1998; see also Rawson, Dunlosky and Thede, 2000). Understanding the nature of this changing experience requires recognition that reading both literary and non-literary texts involves multiple challenges: not only comprehending the foregrounded style choices of an author, but also 'how the events described make 
up the plot, what the interrelationships between characters are, what their behavioural motives are, $[\ldots]$ the reliability of narrators, and so on' (Kuijpers and Hakemulder, 2017: 2).

While a number of questions have yet to be answered, such studies make a clear case for the distinctive nature of re-reading in terms of its experience, processing, and underlying motivations. As Millis et al. (1998) argue, understanding the nature of re-reading is important, and perhaps necessary, if we are to offer a satisfying account of readers' representations and experiences of texts:

It is well accepted that people read to satisfy a number of goals, such as to acquire knowledge and to be entertained (Brewer, 1980). There are other goals that might be addressed by rereading, such as clarifying misconceptions, repairing gaps in the representation, elaborating the text, reexperiencing the text, and verifying and strengthening the content of the reader's passage representation. Rereading is important because some of these processes cannot be easily accomplished with only one reading. (Millis et al., 1998: 244)

One way of better understanding these goals is by asking readers themselves. A final group of articles in our sample features references to re-reading as part of an observation of real readers. While the experiments mentioned previously might be described as 'non-naturalistic' studies of reading (Swann and Allington, 2009), the instances exemplified below are found in 'naturalistic' studies of readers, concerned with readers' experiences of texts in everyday settings such as reading groups, classrooms or online forums.

\#7 S5: Y and then actually on the second reading I didn't feel like that [and] \#8 S1: [mmm] [...]

Like S5 in Example 7, S1 here recounts her experience of reading 'The Dead' twice, saying that the judgements she made after her first reading were greatly altered on her second reading. (Peplow, 2011: 308- 309)

The overwhelming reaction to the poem was that of utter shock and disgust. Some students commented that they had to reread the poem (some more than twice) just to make sure that they understood it correctly; in other words, that someone was actually being eaten. (Bradan, 2012: 125)

For the truly dedicated, Pemberley's Group Reads section offers the opportunity to read or reread all of Austen's novels in rotation. For the even more dedicated, group reads of the letters also take place (Thomas and Round, 2016: 245). 
Such reported experiences of re-reading lend support to our intuitions as to the significance of this practice for readers inside and outside of academia. Given the relatively low frequency with which rereading is explicitly discussed in stylistics, and the questions remaining as to its experience and processing, the extent to which real readers re-read seems an important question to start with. In order to investigate this question empirically, and to gain a more detailed understanding of the types of goals discussed by Millis et al. (1998), we carried out two naturalistic reader response studies of our own. These are outlined in the following sections.

\subsection{Re-reading and real readers}

The first of two studies was designed to investigate the motivations underpinning re-reading habits. An online questionnaire (via Bristol Online Surveys) was distributed to 60 undergraduate students of English at the University of Sheffield and the University of Nottingham, UK. 78\% of the students were female, and the respondents were aged between 17 and 41, with the median age of 20 .

The students were asked firstly to answer questions about their general reading practices:

1) How long does it usually take you to read a fiction book?

2) On average, how many fiction books do you read in six months?

3) Do you re-read books?

The results from the questionnaire indicate that the participants were regular readers of fiction ${ }^{\mathrm{i}} .70 \%$ of the respondents identified that it took them between $<1$ week and 2 weeks to read a book, and again most of the participants (75\%) reported that they read over three books within a six-month period. The results from the re-reading question specifically, however, demonstrate that while some (6.7\%) respondents 'never' re-read books, $0 \%$ identified as 'always' re-reading books. Naturally, this suggests that re-reading is a more selective process than reading itself - there must be specific motivations or reasons that govern the choice to re-read. That being said, re-reading does seem to be a pervasive process, according to our survey, as $93.4 \%$ of the respondents acknowledged that they do re-read with varying degrees of frequency.

The next questions were available only to those who had answered 'yes' to the question concerning re-reading. The re-readers were asked:

4) Why do you re-read books?

5) Which books (or kinds of books) do you re-read? 


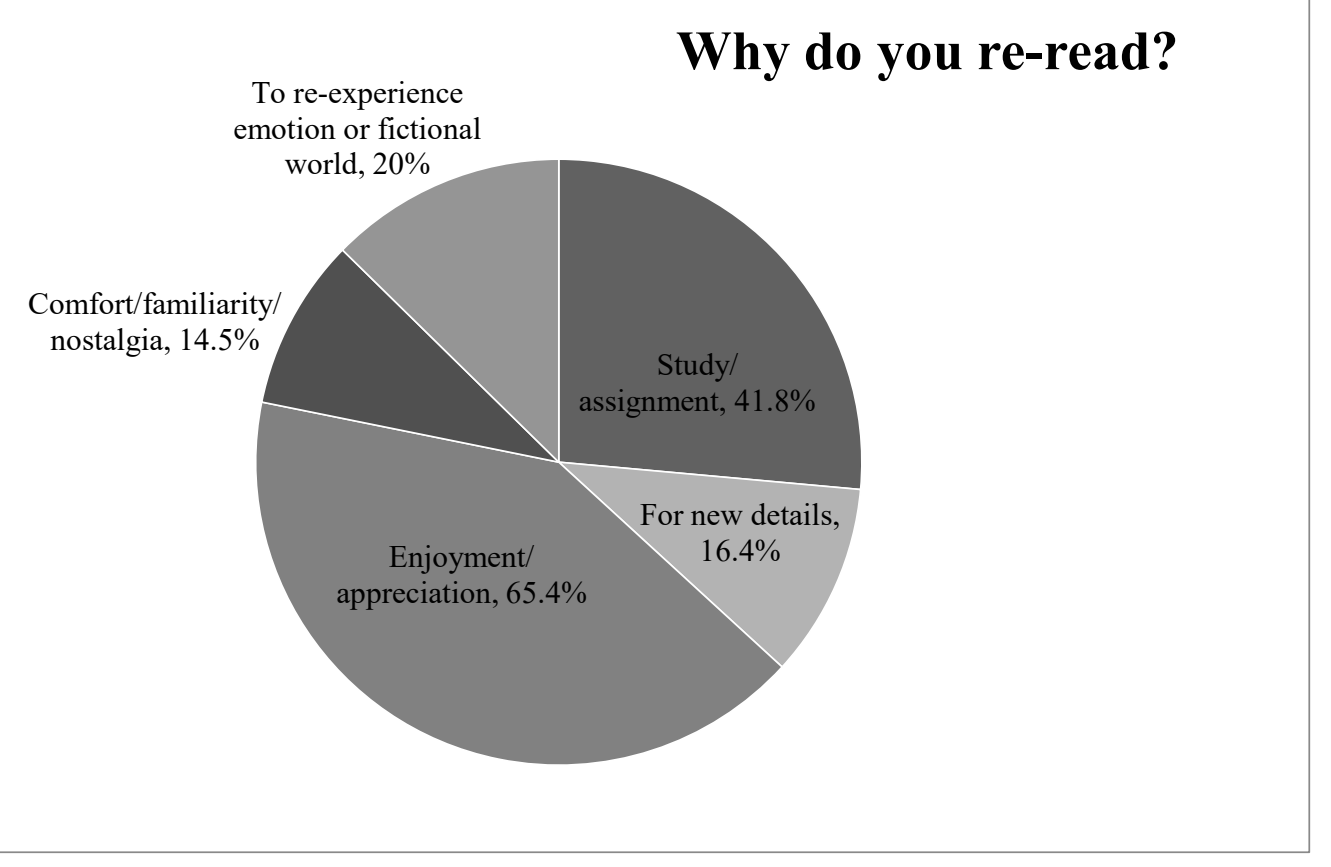

Figure 1. 'Why do you re-read?' responses

The 55 responses to 'why do you re-read' were grouped according to the content of the response, and it was noted that these answers fell into 5 broad categories (please see Figure 1). The 54 responses to 'Which books do you re-read?' again were also grouped according to particular categories, which ranged from the more general (such as simply 'fiction', or 'academic' texts) to the more specific (particular book titles) based on the students' answers. For both questions, the tagging process involved examining the language used by the participants in relation to the salient categories (the category 'To re-experience emotion or fictional world' for Q.4, for example, featured responses such as 'to re-enter the world they create'; 'in order to recapture that feeling or emotion'; 'if the story has very relatable/entertaining characters it is enjoyable to return to'). For both of these questions, some of the responses featured examples from more than one category, and the percentage was calculated based on the number of occurrences within each respective dataset.

The results in the pie chart in Figure 1 demonstrate that the predominant reason for re-reading was either for enjoyment or appreciation of a book. Some of the participants who cited this motivation connected the level of enjoyment with the idea that the text generated some sort of emotional engagement or resonance:

- Because I enjoyed them and grew attached to the characters.

- If i $[s i c]$ especially liked them, or found that they related to another aspect of my life.

- Because I found them enjoyable and found them to relate to something important about my own life.

- Enjoyment if it was a book that I particularly enjoyed or connected with. 
- If there is a part of the plot that I particularly like or that resonates with me, in that I can emphasise with it and find it applicable to my own or others [sic] lives.

The connection between enjoyment and resonance is made either in the sense that readers identify emotional engagement with the characters or novel as a whole (as in the first and fourth responses included above), or that the text 'relate[s] to something important about [their] own life'. In these responses, the participants seem to be describing 'self-implication', or a sense of involvement in a text, through either 'narrative feelings' ('evoked in response to the setting, characters, and events in the imagined world of the text') or through 'evaluative feelings' (in response to 'the text as a whole') (Kuiken et al., 2004: 174-5). The latter are said to 'emerge early within the reading event [and] may affect readers' moods - and their readiness to reread the text - for some time afterward' (2004: 174). Though there is not enough information in the responses to suggest these connections have created 'self-modifying' feelings in the readers, identified by Kuiken et al. (2004: 175) as when readers 'realize something that they have not previously experienced', the feelings of self-implication are clear to see in the evaluative semantic choices used by the respondents to describe the relationship between the text and their own real-world position: 'attached', 'related', 'relate', 'connected', 'resonates', 'applicable'.

The second most prevalent reason (41.8\%) mentioned for re-reading was for university assignments. Interestingly, over a quarter of the participants who referenced this motivator used deontic modality (or negative evaluation, in the case of the final example below), which frames the rereading process as a duty or necessity:

- I have to re-read frequently if i'm [sic] reading texts to analyse for an essay

- or if I am studying the book for class and need to go back to particular sections.

- and if I need to study a particular book in more detail for an assessment

- or if I need to reread something to write an essay or help me with my course

- or if I've read it before and then have to study it

- When I am studying it, and then grudgingly

The responses to Q5 ('Which books/kinds of books do you re-read?') in turn were more disparate, but broadly correlate with the answers to Q4. Many of the responses mentioned that they reread 'fiction' (25.9\%), and some of these responses then went on to specify particular genres of fiction, with the most prominent being fantasy (13\%), thrillers (11.1\%), dystopian and science fiction (9.4\%) and 'classics' (7.4\%). Academic/non-fiction books featured in $20.4 \%$ of the responses, and the non-specific category of 'ones I liked/ enjoyed first time round' was also referenced in $20.4 \%$ of the comments. $11.1 \%$ of the respondents mentioned that they re-read books with which they had 'an [emotional] connection' of some kind, and many of the readers identified specific titles - the two titles 
recurring more than once being Harry Potter (appearing in 7.4\% of the responses) and The Book Thief (5.6\%). The naming of specific texts here is interesting, and arguably suggests that particular books can be said to form a shared cultural reference point for readers and re-reading practices. Further, such results support the idea that 'while [re-reading] is often associated with the 'higher' forms of literature - or perhaps with the traditional canon - it is probably true more widely that people re-read texts they enjoy' (Jeffries, 2001: 328).

Certainly, the results of this study suggest that re-reading is an everyday practice, carried out to achieve a range of goals. As such, these results give support to our original intuitions and correspond with previous research into some of the re-reading motivations discussed in section 1.2, such as the acquisition of knowledge and for entertainment (as outlined in Brewer, 1980). The next section of this paper examines one of these motivations - the aim of 'reexperiencing' the text (Millis et al., 1998: 244) - in greater detail. We argue that the experience invited by a second reading can be very different to that invited by a first reading, and that this difference can be traced to our responses to specific textual cues. While cognitive stylistics offers a comprehensive tool-kit of methodologies through which we can examine these differences, the study in question focuses on the application of schema theory, in particular.

Cognitive stylistics is concerned with the way in which language choices within a text relate to readers' mental processes, and can be seen to focus attention on the movement between linguistic choice and interpretative effect, or the stages of Spitzer's (1948) 'philological circle'. Simpson (2004: 39) argues that while cognitive stylistics 'is intended to supplement, rather than supplant, existing methods of analysis, it does aim to shift the focus away from models of text and composition towards models that make explicit the links between the human mind and the process of reading'. If we hold that re-reading is a basic and essential process within stylistic analysis, then this process becomes one that cognitive stylistics ought to explain.

\subsection{Cognitive stylistics in the classroom}

This final section presents the results of the second reader response study: a classroom exercise on schema theory, carried out in seminars for undergraduate modules in stylistics, with 43 students of English at Coventry University and 17 students of English Language at the University of Huddersfield respectively $\mathrm{ii}$. For both groups of students, the activity we present here took place as part of an introduction to cognitive stylistics.

In their textbook, Stylistics, Jeffries and McIntyre (2010) introduce schema theory as the first framework within the cognitive stylistics tool-kit. Schema theory is the idea that we all have packages of information about certain things, events and situations that can be cued by a text and drawn on during the reading process. These knowledge schemas can be evoked in order to help us understand and process everyday situations, and can be 'reinforced' or 'disrupted' by a discourse (Cook, 1994; 
Semino, 1997). Equally, schemas can be both idiosyncratic and shared by particular cultural groups (Jeffries, 2001). For example, a PUB schema for British people might include certain universal elements such as ordering rounds of drinks, paying at the bar, finding a table, and so on, while some parts of the schema may be individualised (the preferred drinks ordered may vary, for instance). A bartender asking what a customer would like to drink would be a reinforcing act within this schema, whereas the act of a bartender asking the customer for a drink would be considered a disruption of this schema.

Schemas are useful as a starting point for teaching cognitive stylistics as they help us to explore reading as a two-way process, thereby making more 'explicit the links between the human mind and the process of reading' that Simpson (2004: 39) identifies as being integral to a cognitive stylistic approach. In other words, in order to successfully read a text, readers respond to specific language choices, whilst simultaneously drawing on their own ideas and knowledge schemas to more fully conceptualise the fictional world. Schema theory also supports a distinction between the knowledge of reality (world schemas) and the knowledge of textual form and genre (formal schemas) that readers bring to a text, and a discussion of their interaction during reading (Semino 1997: 129). While schema theory is a useful cognitive stylistic tool, its explicit acknowledgement of subjectivity means that sometimes, on first encounters with the model, students can veer too far away from the text. In order to circumnavigate this problem, when teaching schema theory for stylistic analysis it is helpful to outline the specific 'headers' (Schank and Abelson, 1977: 49-50) that texts can use to linguistically cue particular schemas. These will be expanded on in the next sections.

\subsubsection{Reading 1}

The students were first presented with Extract 1 below, the opening passage from the novel The Girl With All The Gifts (Carey, 2014: 1-3). No context for the novel was provided, and the reference information was also originally omitted. The students were asked to read the extract and then answer the questions that followed. Students' responses to these questions are quoted anonymously in our analysis below, using the group/participant identifier we assigned to each questionnaire ('A1', 'B1' etc.). Since this was a seminar environment, while each student was given a separate questionnaire to complete, they did discuss and share ideas. There was also a discussion of the questions and proposed answers at the end of the session. As much as possible, each investigator ensured that the topics of the discussion were student-led.

\section{Extract 1}


Her name is Melanie. It means "the black girl", from an ancient Greek word, but her skin is actually very fair so she thinks maybe it's not such a good name for her. She likes the name Pandora a whole lot, but you don't get to choose. Miss Justineau assigns names from a big list; new children get the top name on the boys' list or the top name on the girls' list, and that, Miss Justineau says, is that.

There haven't been any new children for a long time now. Melanie doesn't know why that is. There used to be lots; every week, or every couple of weeks, voices in the night. Muttered orders, complaints, the occasional curse. A cell door slamming. Then, after a while, usually a month or two, a new face in the classroom - a new boy or girls who hadn't even learned to talk yet. But they got it fast.

Melanie was new herself, once, but that's hard to remember because it was a long time ago. It was before there were any words; there were just things without names, and things without names don't stay in your mind. They fall out, and then they're gone.

Now she's ten years old, and she has skin like a princess in a fairy tale; skin as white as snow. So she knows that when she grows up she'll be beautiful, with princes falling over themselves to climb her tower and rescue her.

Assuming, of course, that she has a tower.

In the meantime, she has the cell, the corridor, the classroom and the shower room [...]

The corridor has twenty doors on the left-hand side and eighteen doors on the right-hand side. Also it has a door at either end. One door is painted red, and it leads to the classroom - so Melanie thinks of that as the classroom end of the corridor. The door at the other end is bare grey steel and it's really, really thick. Where it leads to is a bit harder to say. Once when Melanie was being taken back to her cell, the door was off its hinges, with some men working on it, and she could see how it had all these bolts and sticking out bits around the edges of it, so when it's closed it would be really hard to open. Past the door, there was a long flight of concrete steps going up and up. She wasn't supposed to see any of that stuff, and Sergeant said, "little bitch has got way too many eyes on her" as he shoved her chair into her cell and slammed the door shut. But she saw, and she remembers.

The first two questions asked the students to identify schemas referenced within the text, and then to trace these to specific linguistic evidence (headers). The responses suggested that the three schemas that were most prominent were PRISON, FAIRYTALES and SCHOOL/EDUCATION, with a number of students elaborating on the latter to identify specifically an ORPHANAGE schema. These schemas were traced to particular headers within the text: 


\begin{tabular}{|l|l|l|}
\hline Schema & Character roles & Locale headers \\
\hline PRISON & 'Sergeant' & $\begin{array}{l}\text { 'cell door'; 'cell'; 'concrete steps'; } \\
\text { 'thick' door of 'bare grey steel' with } \\
\text { 'all these bolts and sticking out bits } \\
\text { around the edge of it' }\end{array}$ \\
\hline FAIRYTALES & 'princess'; 'princes'; & 'tower' \\
\hline SCHOOL/EDUCATION & $\begin{array}{l}\text { 'Miss Justineau'; 'new } \\
\text { children'; 'a new boy or } \\
\text { girls' }\end{array}$ & 'classroom'; 'corridor' \\
\hline
\end{tabular}

Table 2. Schema identification on first reading

The combination of certain character roles (listed in Table 2) alongside particular descriptions of location reinforced the connections between these schemas. Furthermore, many students also identified a crossover between schemas, and acknowledged that some descriptions in the text helped support more than one schema simultaneously. The descriptions of Melanie's location, for example, suggested that she is attending a school set-up, but seemingly against her will - and this combined MILITARY/ SCHOOL schema forms a more superordinate INSTITUTION schema on first reading of the text. In thematic contrast to the references to the INSTITUTION schema, many students also acknowledged the descriptions of FAIRYTALE elements in the narrative. Again, while there are explicit roles that indicate this, one student commented on the fact that additionally a structural FAIRYTALE template was evoked by the exposition at the beginning of the story: as in other fairytales, the story is framed by an explicit introduction to the protagonist ('Her name is Melanie') and a description of her physical appearance ('Now she's ten years old [with] skin as white as snow').

The third question asked the students, firstly, to identify the genre of the text and to consider whether it reminded them of other narratives; and secondly, what it was about the text that led them to this categorisation. Significantly, despite the lack of context provided for the novel, the most popular categorisation for the text (a third of the responses) identified it as a dystopian text, with 5 students comparing it with The Handmaid's Tale (Atwood, 1985), in particular. Students acknowledged that the situation is represented as 'secretive' (B4) and proffers a 'sense of entrapment' (B7) and 'imprisonment' (B1), and that these features, in addition to the emphasis on the description of the location and the representation of 'the character facing the challenge of escaping' (A6), connected this text to the dystopian genre. Additionally, justification for this categorisation was also linked to the juxtaposition of schemas in the text. The FAIRYTALE schema is undermined by dysphemistic language 
choices ("little bitch has got way too many eyes on her"), for example, with one student acknowledging this clash by describing the text as 'The Handmaid's Tale meets Oliver Twist' (A13). Other popular classifications for the text included science fiction (15\%), fantasy (15\%) and psychological/action thrillers (15\%), which again were connected with particular style choices. The hinting at 'experimentation' (A15) or 'reconditioning' (B12) and the emphasis on 'hidden events' were identified as features of science fiction, while the fact that the protagonist is a child (A9) was seen as a hallmark of the fantasy genre, and the 'ambiguous setting' (B6) and representation of 'confinement' (B11) as features of thrillers. Children's fiction (8\%) was another genre mentioned by the students, which in turn was connected to the predominance of the ORPHANAGE schema. Other students commented on the fact that this clash may be due to the worldview of the focaliser, Melanie, though: C10 argued, for example, that the references to be fairytales 'is likely a coping mechanism' for the distressing situation she is presented with, while A11 questions whether the description is being filtered subjectively ('Is it a cell or her view of her room?').

In summary, the results of the first reading indicated that this introduction to the text displays a clash of schema templates. It is this clash, in particular, that creates the 'unsettling' (C11), 'mysterious' (A9) and 'eerie' (A1) atmosphere on first reading of this text, and one which possibly foreshadows events to come.

\subsection{2. $\quad$ Reading 2}

In the second half of the study, the students were given the following context for the extract: the novel is a dystopian narrative that outlines a future world where zombies, 'hungries', have taken over the world. It is revealed a couple of pages into the novel that Melanie and the other children in the class are hungries; restrained and imprisoned for the safety of the people that watch over them. This knowledge of genre and plot was intended to replicate, approximately, the basic knowledge that would be revealed by the text itself were the students to read it in full and then return to the opening extract for a second reading.

The students were then asked to re-read the extract, and to identify any headers that activated a different schema, or that carried new significance on second reading. Many of the students acknowledged the descriptions of the school set-up as being altered. What seemed like a process for taking a register on first reading ('Miss Justineau assigns names from a big list; new children get the top name on the boys' list or the top name on the girls' list'), for example, becomes altered so that the assignation of names, rather than the 'big list' of names itself, is foregrounded. Equally, the students identified the fact that a sense of narrative time also becomes prominent, and highlighted that the text makes vague references to a time 'before', and to the background of these children ('Boys or girls who hadn't learned to talk yet'). Most notably, the students discussed how the descriptions of security measures gained increased significance. While the emphasis on the description of location and 
impressions of imprisonment were noted on first reading, it becomes more apparent that these security measures are to confine the children - not to keep them safe, but because they are dangerous. The detailed description of the door (made of 'really, really thick' steel) becomes a signpost for 'the strength of the children' (A13) and the threat they represent.

Furthermore, the students also began to make assumptions about the wider narrative development on a re-reading. Both the significance of the name 'Pandora', and the suggestion that the door to the cell might be faulty (Melanie describes how once there were 'some men working on it'), were noted as potentially foreshadowing events to come, underscored by the ominous final line: 'But she saw, and she remembers'.

In addition to altered significance, some of the textual headers were seen to activate multiple schemas that became apparent on a re-reading. That Melanie is described as 'very fair' and with 'skin as white as snow', for example, was identified as a header for the FAIRYTALE schema on the first reading, but also to initiate a ZOMBIE schema on second reading. Additionally, the description of the 'tower' again suggests both FAIRYTALE and IMPRISONMENT schemas, simultaneously, while for some students the references to Melanie's 'chair' was indicative of DISABILITY on first reading, but PRISON on a second. Finally, for some students, the second reading experience foregrounded schemas that were hidden or 'buried' (Emmott and Alexander, 2014) on first reading. The description of the classroom door as being 'painted red', for example, was construed as symbolic of danger - but only during re-reading.

In summary, the stylistic effect of the activation of schemas on a first reading is that it 'keeps you off the trail' (C14) of identifying the exact nature of the text and its characters. Consequently, the students discussed how feelings of sympathy and empathy for Melanie and the rest of the hungries are created in the text: the schemas initiated on a first reading play a key role in building up our mental perception of the children, and work to humanise them. Clearly, a second, more informed, reading of this text offers up a different experience to the first reading. While the responses to the first reading demonstrated how the clash of schema templates creates a feeling of unease among readers, the second reading shows how different domains of knowledge are activated through the same textual cues in light of the genre and plot information we revealed. Arguably what happens here, for readers encountering the extract a second time, is a process of schema adjustment that is driven by their altered sense of its context. The feelings of empathy created for the hungries on a first reading elicits a wider schematic shift about the nature of such 'zombie apocalypse' texts. Stereotypically, such characters are represented as hostile antagonists, but the representation of these characters as more human-like and deserving of sympathy inverts our expectations for this type of narrative. The second reading works to normalise the schema clashes and instead reinforce the connections between these textual cues, which ultimately 'refreshes' (Cook, 1994) readers' mental template for this genre.

Clearly, this study does not replicate the actual experience of reading and re-reading this 500 page novel. Besides the practical difficulties in requiring students to commit to a full solitary reading 
before class, or indeed a paid study, even a successful longitudinal study of this kind could not capture the variation in knowledge that readers bring to texts on a second reading, or the different lengths of time which intervene between readings in natural re-reading. Given this complexity, stylistic reader response studies such as this are inevitably limited to controlled examinations of re-reading under specific conditions, the findings of which are often difficult to generalise. Nonetheless, we would argue that a systematic, qualitative analysis of re-reading such as that demonstrated here offers a means of investigating (and encouraging students to investigate) the nature of the real world reading experiences we discuss in stylistics.

\subsection{Conclusion: Re-reading and pedagogy}

This paper has explored the place of re-reading in stylistics, and has made proposals for its treatment going forward. It was identified that while references to re-reading (and other variations of the term) are found alongside references to 'reading' and 'readers' in stylistics research, they are far less frequent. While differences in the felt experience of first and second readings of texts are often noted, these are most often based on introspection and theoretical speculation. Finally, while discussions of re-reading can be found based on naturalistic and experimental reader response data (e.g. Bradan, 2012; Cui, 2017; Kuijpers and Hakemulder, 2017), there has been no sustained treatment of first and second reading experiences in stylistic or cognitive stylistic terms. While recognising that re-reading is an intrinsic part of stylistic analysis and a pervasive feature of reader experiences outside academia, it seems that this practice has yet to be properly scrutinized.

As a way into this discussion, the second section of this article presented the results of a survey of re-reading habits amongst students of English Language and Literature in two UK universities. This survey highlighted a range of motivations for re-reading and its potential significance for students. It was observed that those students who re-read for enjoyment, often reported experiences of self-implication in the text, such as immersion, identification or emotional resonance, as a motivation for re-reading. Re-reading for assignment purposes, on the other hand, was described in more resistant terms; with (deontic) modalisation and negative evaluation.

The third and final section of this article offered a re-reading case study in the form of a cognitive stylistics exercise carried out in the undergraduate classroom. As an example of systematic re-reading in stylistics teaching, this exercise highlights the value of comparing first and second readings in two main respects.

Firstly, we argue that emphasis upon the differences of interpretation brought about by rereading invites a greater appreciation of the text and its linguistic choices (Dixon et al., 1993). The qualitative study of naturalistic reader response data demonstrated here can be seen to contribute to this line of empirical research in stylistics, by beginning to tackle the nature of the 'emergent effects' identified quantitatively in previous studies. In the case of the novel we considered here, these 
emergent effects consisted of a process of schema adjustment when re-reading this text, the creation of feelings of empathy for the 'hungries', and a refreshment of readers' formal schema for the genre as a whole. A clear delineation of readings in stylistic analysis offers one way of developing an understanding of the processes which underpin these effects. Further, explicit acknowledgement of readers' active roles in the diachronic construction of textual meaning serves to emphasise the 'authentic reading' (Giovanelli and Mason, 2015) of a text, as opposed to their treatment as inflexible cultural artefacts to be studied and understood. This issue could have implications for wider debates in UK education about the treatment of English as a school subject and, in particular, its varying conceptions as a discipline which facilitates personal responses to texts, or rather the ability to respond appropriately to a shared cultural heritage (Mason and Giovanelli, 2017: 325; see also Gibbons, 2013; Marshall, 2000). In practical terms, understanding the kinds of processing and experiential differences that distinguish (re)readings has relevance beyond undergraduate teaching, for example, in the teaching of English Language/and Literature in secondary education, where students are variably assessed on their ability to analyse texts encountered for the first time under exam conditions, or those texts previously read (and re-read) in class (e.g. AQA 2014, 2018).

Secondly, we argue that the systematic discussion of multiple readings as part of a stylistic analysis offers a means of testing existing models of discourse processing in (cognitive) stylistics. In her critical examination of schema theory, Jeffries notes a number of questions which arise when rereading is taken into account:

The problem [re-reading] raises for the proposed schema-change function of literature is that it leads us to hypothesize that it is, indeed, a feature of higher literature, because such texts have a capacity for continuing to change the reader's schema however often they are read. Alternatively we would have to accommodate re-reading within the model as an occasion when we enjoy remembering our schema being changed on the first reading. Even a combination of these approaches, which is probably theoretically possible, would, in my view, not be a satisfactory account of the re-reading process. Not only does it not seem to describe adequately what happens when we read a favourite work, but it hints at one of the general issues that arise from cognitive models such as schema theory: the question of whether these models are intuitively satisfying. (2001: 328)

The study presented here represents a worked out example of this re-reading process in schema theory terms, which to us seems intuitively satisfying. Examination of the different ways in which other texts reinforce, disrupt or change readers' schematic knowledge during re-reading, and the challenges they present to this cognitive theory, offers a means of developing (or rejecting) such models in stylistics. Applications of cognitive discourse models such as Text World Theory (Gavins, 2007) and Cognitive Grammar (Harrison et al., 2014) over multiple readings might offer similar benefits. 
Though basic in design, the Girl With All The Gifts exercise presented here, we hope, lends itself to replication by fellow teachers and researchers, as a way of acknowledging re-reading in text analysis and highlighting the significance of 'authentic' and naturalised reading experiences. Other possible classroom exercises could include an examination of the differences between solitary and social readings (Peplow et al., 2016), with students asked to read a text individually before re-reading as a group (and vice versa); or the examination of intertextuality through explicit re-reading of a text following exposure to other related discourses- either within or across seminar sessions. While some of these practices are already performed in English degrees- it is assumed (or hoped), for example, that students will have read the reading list before class- more explicit treatment and acknowledgement of the dynamic nature of reader experience may enhance the study of these texts, and subsequent discussions of the literature.

\section{References}

AQA (2018) AS and A-Level English Language and Literature Specification: AS (7706), A-level (7707), Version 1.2 January 2018. Available at: http://filestore.aqa.org.uk/resources/english/specifications/ (accessed 23 Feb 2017). AQA (2014) AS and A-Level English Language Specification: AS(7701), A-level(7702), Version 1.0 14 October 2014. Available at: http://filestore.aqa.org.uk/resources/english/specifications/ (accessed 23 Feb 2017).

Bhaya Nair R (2003) Sappho's daughters: postcoloniality and the polysemous semantics of gender. Journal of Literary Semantics 32(2): 113-132.

Bradan D (2012) Metaphor as argument: a stylistic genre-based approach. Language and Literature 21(2): 119-135.

Bray J (2007) The 'dual voice' of free indirect discourse: a reading experiment. Language and Literature 16(1): 37-52.

Brewer WF (1980) Literary theory, rhetoric, stylistics: implications for psychology. In: Spiro JR, Bruce BC and Brewer WF (eds) Theoretical Issues in Reading Comprehension. Hillsdale, NJ: Erlbaum, pp. 221-239.

Burke M (2010) Why care about pedagogical stylistics? Language and Literature 19(1): 7-11.

Caink A (2008) Experiencing meanings in Spark's The Prime of Miss Jean Brodie. Journal of Literary Semantics 41(2): 121-138.

Carey MR (2014) The Girl With All The Gifts. London: Orbit.

Castiglione D (2017) Difficult poetry processing: reading times and the narrativity hypothesis. Language and Literature 26(2): 99-121. 
Csatár P, Pethő G and Tóth E (2006) On possible factors in the aesthetic appreciation of metaphors. Journal of Literary Semantics 35: 59-71

Cook G (1994) Discourse and Literature. Oxford: Oxford University Press.

Cui Y (2017) Reader responses to shifts in point of view: an empirical study. Language and Literature 26(2): 122-136.

Dixon P, Bortolussi M, Twilley LC and Leung A (1993) Literary processing and interpretation: towards empirical foundations. Poetics 22: 5-33.

Emmott C (2003) Reading for pleasure: a cognitive poetic analysis of 'twists in the tale' and other plot reversals in narrative texts. In: Gavins J and Steen G (eds) Cognitive Poetics in Practice. London: Routledge, pp. 145-160.

Emmott C and Alexander M (2014) Foregrounding, burying and plot construction. In: Stockwell P and Whiteley S (eds) The Cambridge Handbook of Stylistics. Cambridge: Cambridge University Press, pp. 329-344.

Emmott C, Sanford AJ and Morrow LI (2006) Capturing the attention of readers? Stylistic and psychological perspectives on the use and effect of text fragmentation in narratives. Journal of Literary Semantics 35(1): 1-30.

Furlong A (1996) Relevance Theory and Literary Interpretation. $\mathrm{PhD}$ thesis, University College London.

Gavins J (2007) Text World Theory: An Introduction. Edinburgh: Edinburgh University Press.

Gavins J and Stockwell P (2012) About the heart, where it hurt exactly, and how often. Language and Literature 21(1): 33-50.

Gibbons S (2013) The London Association for the Teaching of English 1947-67: A History. London: Trentham Books.

Gibbs R (2002) Identifying and appreciating poetic metaphor. Journal of Literary Semantics 31: 101112

Giovanelli M and Mason J (2015) 'Well I don't feel that': Schemas, worlds and authentic reading in the classroom. English in Education 49(1): 41-55

Hakemulder F (2004) Foregrounding and its effect on readers' perception. Discourse Processes 38(2): 193-218.

Hakemulder F (2007) Tracing foregrounding in responses to film. Language and Literature 16(2): $125-139$.

Harrison $\mathrm{C}$ and Nuttall L (Forthcoming) Cognitive Grammar and reconstrual: Re-experiencing Margaret Atwood's 'The Freeze-Dried Groom'. In: Neuorohr B and Stewart-Shaw L (eds) Experiencing Fictional Worlds. Amsterdam: John Benjamins.

Harrison C, Nuttall L, Stockwell P and Yuan W (eds) (2014) Cognitive Grammar in Literature. Amsterdam: John Benjamins. 
Iser W (1974) The Implied reader: Patterns of Communication in Prose Fiction from Bunyan to Beckett. London: John Hopkins.

Jeffries L (2001) Schema affirmation and white asparagus: Cultural multilinguialism among readers of texts. Language and Literature 10(4): 325-43.

Jeffries L and McIntyre D (2010) Stylistics. Cambridge: Cambridge University Press.

Kuijpers MM and Hakemulder F (2017) Understanding and appreciating literary texts through rereading. Discourse Processes: 1-23.

Kuiken D, Miall D and Sikora S (2004) Forms of self-implication in literary reading. Poetics Today 25(2): 171-203.

Marshall B (2000) English Teachers: The Unofficial Guide: Researching the Philosophies of English Teachers. London: Routledge.

Mason J and Giovanelli M (2017) 'What do you think?' Let me tell you: Discourse about texts and the literature classroom. Changing English 24(3): 318-329.

Millis KK (1995) Encoding discourse perspective during the reading of a literary text. Poetics 23(3): $235-253$.

Millis KK, Simon S and TenBroek NS (1998) Resource allocation during the rereading of scientific texts. Memory and Cognition 26(2): 232-46.

Nuttall L (2015) Attributing minds to vampires in Richard Matheson's I Am Legend. Language and Literature 24(1): 23-39.

Peplow D (2011) 'Oh, I've known a lot of Irish people': Reading groups and the negotiation of literary interpretation. Language and Literature 20(4): 295-315.

Peplow D, Swann J, Trimarco P and Whiteley S (2016) The Discourse of Reading Groups: Integrating Cognitive and Sociocultural Perspectives. London: Routledge.

Prusse MC (2012) Repetition, difference and chiasmus in John McGahern's narratives. Language and Literature 21(4): 363-80.

Rawson KA, Dunlosky J and Thiede KW (2000) The rereading effect: Metacomprehension accuracy improves across reading trials. Memory \& Cognition 28: 1004-1010.

Schank R and Abelson R (1977) Scripts, Plans, Goals and Understanding. An Inquiry into Human Knowledge Structures. Hillsdale: Lawrence Erlbaum Associates.

Semino E (1997) Language and World Creation in Poems and Other Texts. London: Longman.

Short M (1996) Exploring the Language of Poems, Plays and Prose. Harlow: Pearson Education.

Simpson P (2004) Stylistics: A Resource Book for Students. London: Routledge.

Sorlin S (2015) Person deixis and impersonation in Iain Banks's Complicity. Language and Literature 24(1): 40-53.

Spitzer L (1948) Linguistics and Literary History: Essays in Stylistics. Princeton, NJ: Princeton University Press. 
Stanovich KE and West RF (1989) Exposure to print and orthographic processing. Reading Research Quarterly 24(4): 402-433.

Sternberg M (2001) How narrativity makes a difference. Narrative 9(2): 115-122.

Stockwell P (2002) Cognitive Poetics: An Introduction. London: Routledge.

Stockwell P and Whiteley S (eds) (2014) The Cambridge Handbook of Stylistics. Cambridge:

Cambridge University Press.

Swann J and Allington D (2009) Reading groups and the language of literary texts: a case study in social reading. Language and Literature 18(3): 247-64.

Thomas B and Round J (2016) Moderating readers and reading online. Language and Literature 25(3): 239-53.

Verdonk P (2005) Painting, poetry, parallelism: Ekphrasis, stylistics and cognitive poetics. Language and Literature 14(3): 231-244.

Whiteley S and Canning P (2017) Reader response research in stylistics. Language and Literature 26(2): 71-87.

Wood T (2004) Cognitive processes in text interpretation: rereading Bakhtin. Journal of Literary Semantics 33(1): 25-40

Yaron I (2003) Mechanisms of combination in the processing of obscure poems. Journal of Literary Semantics 32(2): 151-66.

Zyngier S, van Peer W and Hakemulder F (2007) Complexity and foregrounding: In the eye of the beholder? Poetics Today 28(4): 653-682.

\footnotetext{
${ }^{\mathrm{i}}$ The accuracy of self-reports of reading frequency is questionable, with the possibility of exaggeration for reasons of social desirability (see also Kuijpers and Hakemulder, 2017: 5). To limit this effect in our study, we disseminated our study online to students at other institutions to our own, where the motivation to impress us as researchers might be lessened. An alternative means of reducing this effect would be to use the Author Recognition Test (ART; Stanovich and West, 1989).

ii The stylistics modules in which this activity took place included students from a range of courses at both Universities, including: English and Creative Writing, English Language with Creative Writing, English Language \& Linguistics, English Literature, English Language and Literature.
} 